\title{
Reducing sugar, fat, and salt for prevention and control of noncommunicable diseases (NCDs) as an adopted health policy in Iran
}

\author{
Mohammad Amerzadeh ${ }^{1}$, Amirhossein Takian*1,2,3 (D) \\ Received: 15 Mar 2019 \\ Published: 13 Oct 2020
}

\section{Abstract}

Background: Tackling noncommunicable diseases (NCDs) and their multifaceted, complex risk factors requires identifying policy gaps and translation of successful experiences for each setting. As advocated by World Health Organization (WHO), reducing sugar, salt, and fat are among best buys for prevention and control of NCDs. This article reports the status of existing policies to reduce the consumption of sugar, salt, and fat in Iran.

Methods: We created a comprehensive repository of available policy documents about sugar, salt, and fat policies in Iran and conducted content analysis and interviews with relevant stakeholders. Then, we compared policies and their content with the WHO's best buys' recommendations.

Results: We categorized policies in 3 groups: red colour (no mention in the policy documents), amber (inspirational policy mention without action), and green (policy in operation). For example, regarding sugar, we found 8 policies in green, 1 in amber. Our matrix of policies on all 3 topics created a platform for further policy analysis and transferrable lessons to improve national actions towards $30 \%$ reduction of death due to NCDs in Iran.

Conclusion: It has been globally recognized that beyond technical solutions to combat NCDs, feasible and meaningful policy solutions must be created that are aligned with the political economy of each context. This necessitates learning from national, regional, and global experiences to manage the political economy of NCDs' main determinants. To this end, our study provides a systematic and evidencebased framework, which may also be beneficial for other nations.

Keywords: Salt, Sugar, Fat, Iran, Best buys

Conflicts of Interest: The corresponding author is a member of the Iranian National Committee for Prevention \& Control of NCDs.

Funding: The study that resulted in this article was partially funded as a PhD thesis of health policy at the Tehran University of Medical Sciences (TUMS).

\section{*This work has been published under CC BY-NC-SA 1.0 license.}

Copyright $₫$ Iran University of Medical Sciences

Cite this article as: Amerzadeh M, Takian A. Reducing sugar, fat, and salt for prevention and control of noncommunicable diseases (NCDs) as an adopted health policy in Iran. Med J Islam Repub Iran. 2020 (13 Oct);34:136. https://doi.org/10.47176/mjiri.34.136

\section{Introduction}

Noncommunicable diseases (NCDs) are considered the biggest and fastest growing danger to human well-being, particularly in low- and middle-income countries (LMICs) context (1). Of annual deaths, $71 \%$ are attributed to NCDs, which kill 15 million people aged 30-69 years, accounting for $85 \%$ of premature deaths occurring in the LMICs, most

Corresponding author: Dr Amirhossein Takian, takian@tums.ac.ir

1. Department of Health Management and Economics, School of Public Health, Tehran University of Medical Sciences, Tehran, Iran

2. Department of Global Health and Public Policy, School of Public Health, Tehran University of Medical Sciences, Tehran, Iran

3. Health Equity Research Centre (HERC), Tehran University of Medical Sciences, Tehran, Iran of which are preventable (2). The Global Burden of Disease (GBD) study identified NCDs as the most significant contributor to both burden of disease (as measured through DALYs, ) and death in the Middle East and North Africa (MENA) region (3).

\section{$\uparrow$ What is "already known" in this topic:}

Many studies have been conducted on salt, sugar, and fat distinctly, but no coherent study has considered policies regarding these 3 components in Iran. In addition, to date, no study has compared the existing policies with best buys. recommendations.

\section{$\rightarrow$ What this article adds:}

This paper presents the findings of a comprehensive study that aimed to clarify the status of national policies about salt, sugar, and fat in Iran, in line with WHO's best buys and other related interventions. 
Traditionally, there are 4 main NCDs: cardiovascular diseases, cancer, chronic respiratory diseases, and diabetes are driven mainly by 4 main risk factors: tobacco use, unhealthy diet, physical inactivity, and harmful use of alcohol. WHO introduced the association as $4 \mathrm{X} 4$ model. NCDs are also a major cause of poverty and an obstacle to economic and social improvement. The UN Political Declaration of 2018 on NCDs added air pollution as the fifth risk factor and mental and neurological conditions as the fifth category of disease to the list, rebranding a more comprehensive ' $5 \times 5$ ' model for NCDs management and control (4). As a result, the model addresses 5 major diseases, including cardiovascular diseases, cancer, chronic respiratory diseases, diabetes, and mental and neurological conditions, and 5 risk factors, including tobacco use, unhealthy diet, physical inactivity, harmful use of alcohol, and air pollution.

Globally, dietary risk factors and physical inactivity are responsible for approximately $10 \%$ of the burden of disease (5). The World Health Assembly (WHA) has confirmed a set of 9 voluntary targets to reduce behavioral and physiological risk factors for NCDs, e.g. a target of reducing mean population salt intake by $30 \%$ by 2030 , a $25 \%$ relative reduction in the overall mortality from cardiovascular diseases, cancer, diabetes, or chronic respiratory diseases, and halting the rise in diabetes and obesity (6).

In 2017, NCDs killed 291000 people in Iran. The ascending trends of disability-adjusted life years (DALYs) and death during the past decades shows the serious threat of NCDs, including premature death and many disabilities (7, 8 ). For instance, 6.5 million years of life lost (YLLs) and 8.2 million years lived by disability (YLDs) were the dramatic signs of emerging burden of NCDs in 2016 in Iran (9). The 4 main NCDs are responsible for $81 \%$ of premature deaths in Iran (10). Moreover, dietary risks are among the first line of NCDs' risk factors in Iran (11).

Further, the economic burden of NCDs and its impact on productivity reduction is considerable. Poor people struggle more with health expenditure and living costs $(10,12)$. The first reason of catastrophic health expenditures is related to NCDs, reinforcing the key position of social inequities in this regard (13). By introducing the so-called public health best buys, the WHO aimed to present the most cost-effective interventions to reduce NCDs' risk factors at the population level, which include tobacco-control measures, reducing salt intake, replacing trans fats in foods with polyunsaturated fats, promoting public awareness about diet and physical activity, and delivering hepatitis B vaccinations (14). The widespread implementation of best buys, along with primary health care (PHC) measures, need only a modest investment and may potentially end up to fast gains in counteracting the effects of NCDs (14).

Many countries have reported the effect of populationbased salt reduction and the anticipated health benefits in this intervention as a cost-effective best buy. There are few examples of successful models in the LMICs that address the complex governance of the disease-inducing elements found in the near-ubiquitous commercial commodities, such as food, sweetened beverages, and alcohol (14). Our study aimed to identify potentially appropriate governance mechanisms with potential positive impacts on the rates of risk exposure and to determine the alignment of these policies based on best buys recommendations. This article reports the status of existing policies to reduce sugar, salt, and fat consumption in Iran.

\section{Methods}

We created a comprehensive repository of available policy documents about sugar, salt, and fat policies in Iran and conducted a content analysis. We also interviewed relevant stakeholders. Our interview guide was prepared based on Government Healthy Food Environment Policy Index (Food-EPI) monitoring tool (15), which has 2 components: policies and infrastructures. We used health policy triangle framework (16) for deductive analysis. Also, we compared policies and their content with the WHO's best buys recommendations, aiming to identify how practices can be scaled up nationally and what lessons can be learnt crossnationally based on best buys interventions.

Initially, we gathered and studied all upstream and downstream policies in Iran regarding salt, fat, and sugar since 2003, when the Supreme Council for Health and Food Security (SCHFS) was established. We followed a 4-step Scott method to determine authenticity, credibility, representativeness, and meaningfulness of data (17). First, to assure authenticity, we investigated the offering source of documents and verified the ones issued by the Parliament, the Government, and SCHFS as authentic. Second, to determine credibility, we verified only those documents that were not misleading or biased and were without any personal and organizational conflict of interest. Third, representativeness meant that the investigated documents presented general policies or specific keywords on the basis of our research objectives. Finally, we ensured meaningfulness by determining that the document was comprehensible and comprehensive with respect to face and content validity. Therefore, all documents that missed even one of the quadruple Scott's indices were excluded from the content analysis. Finally, we conducted the content analysis of the identified documents using a mixed (inductive and deductive) approach (18). The included documents came from a diverse group of proposed policies, laws, and regulations. Table 1 represents the list of upstream and downstream policies included in this study.

We used a color-based presentation to categorize our findings as below:

Red $=$ no mention in the policy documents;

Amber = topic is mentioned but it appears to be aspirational (eg, "We will plan to...") rather than an actual policy/strategic action in place;

Green $=$ topic is mentioned and policy/strategic action is in place.

\section{Results}

\section{Best Buys criteria}

Figure 1 presents the sugar polices status in Iran, based on WHO best buys recommendations. Most policies are green, only 1 is amber, and there is no red area in this domain. Figure 2 shows the salt polices status in Iran, based on global best buys recommendations, indicating that all polices are green. Figure 3 shows the trans-fat polices status 
Table 1. The upstream and downstream policies regarding salt, sugar, and fat in Iran

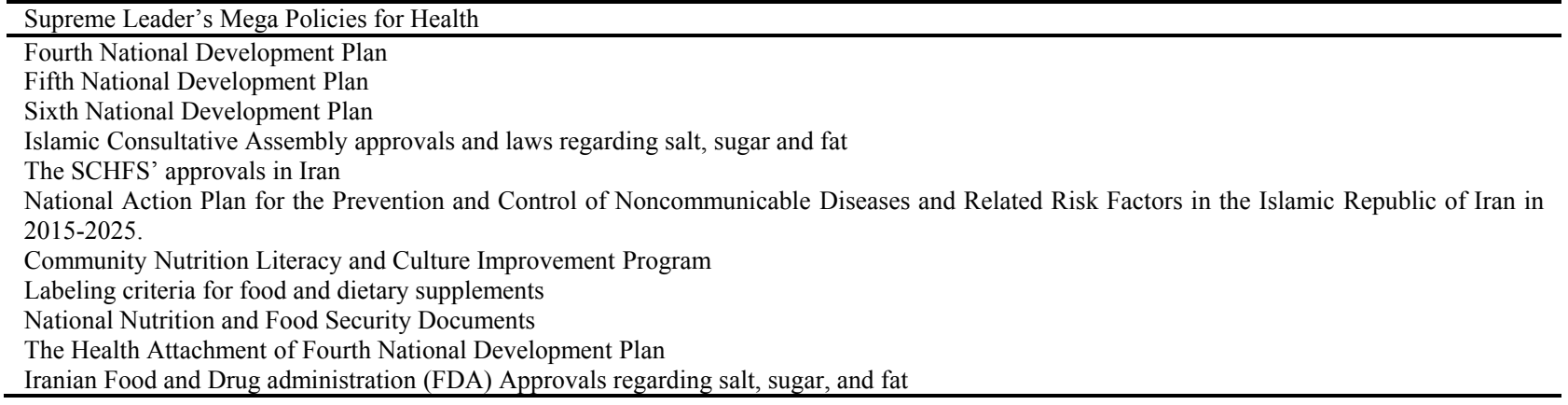

in Iran, based on global best buys recommendations, indicating that all polices are green.

\section{Discussion}

The status of best buys-related policy content is generally advance in Iran. Our analysis revealed that 20 policies are

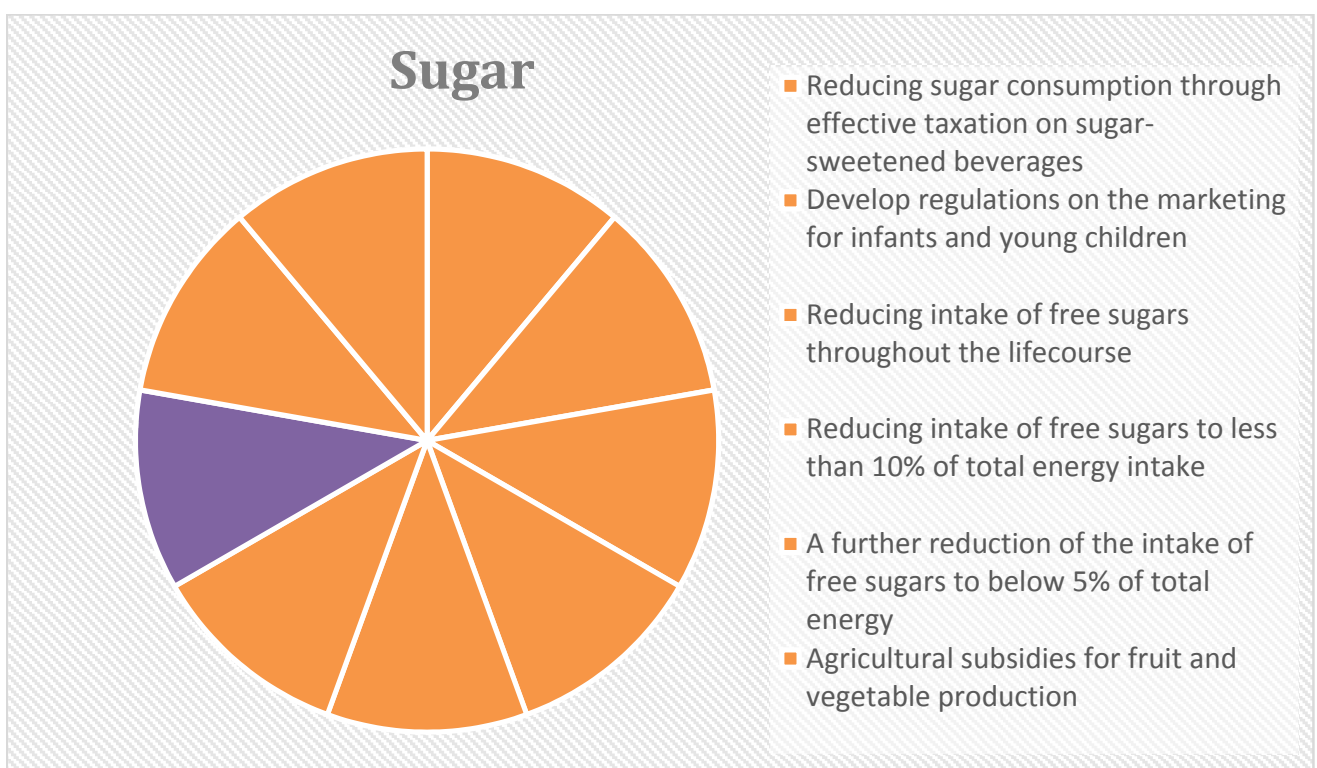

Fig. 1. The sugar polices status in Iran based on Global Best Buys recommendations

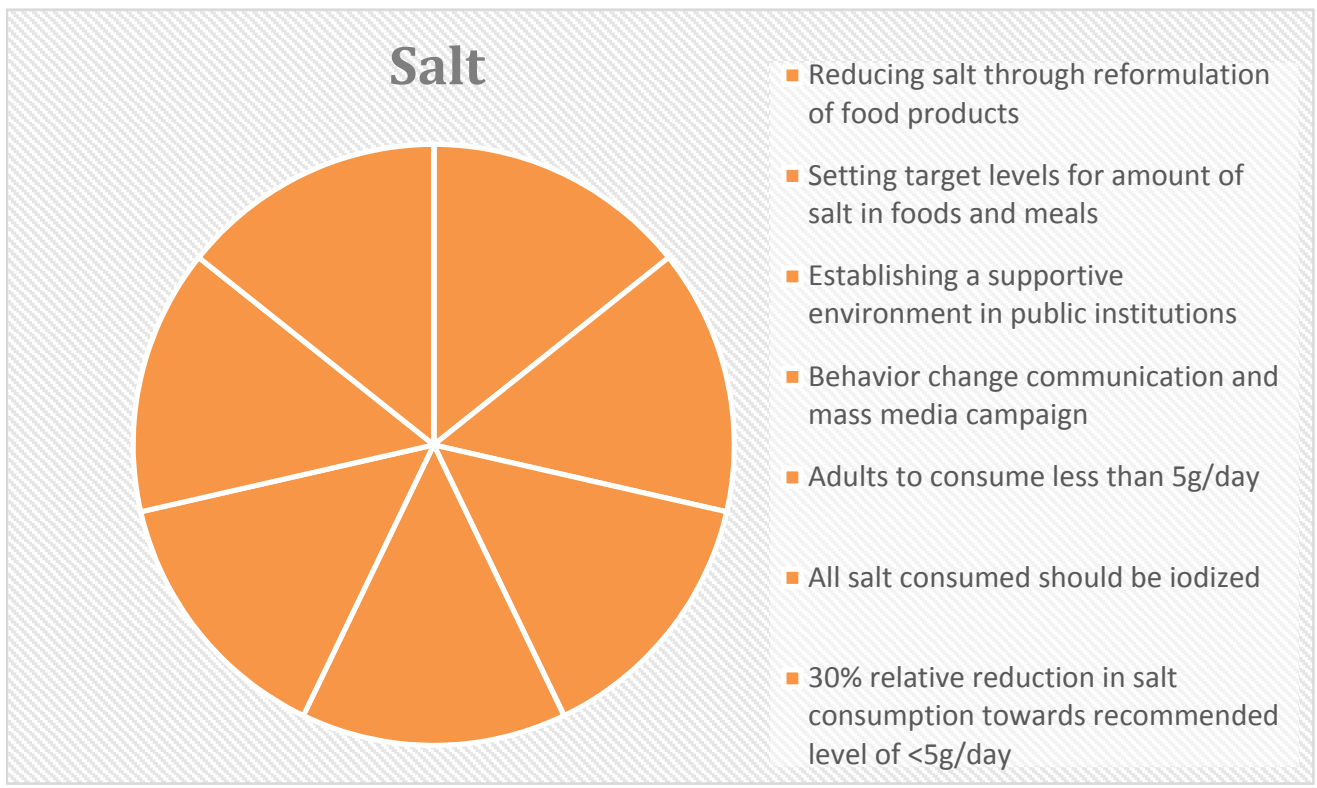

Fig. 2. The salt polices status in Iran based on best buys recommendations 


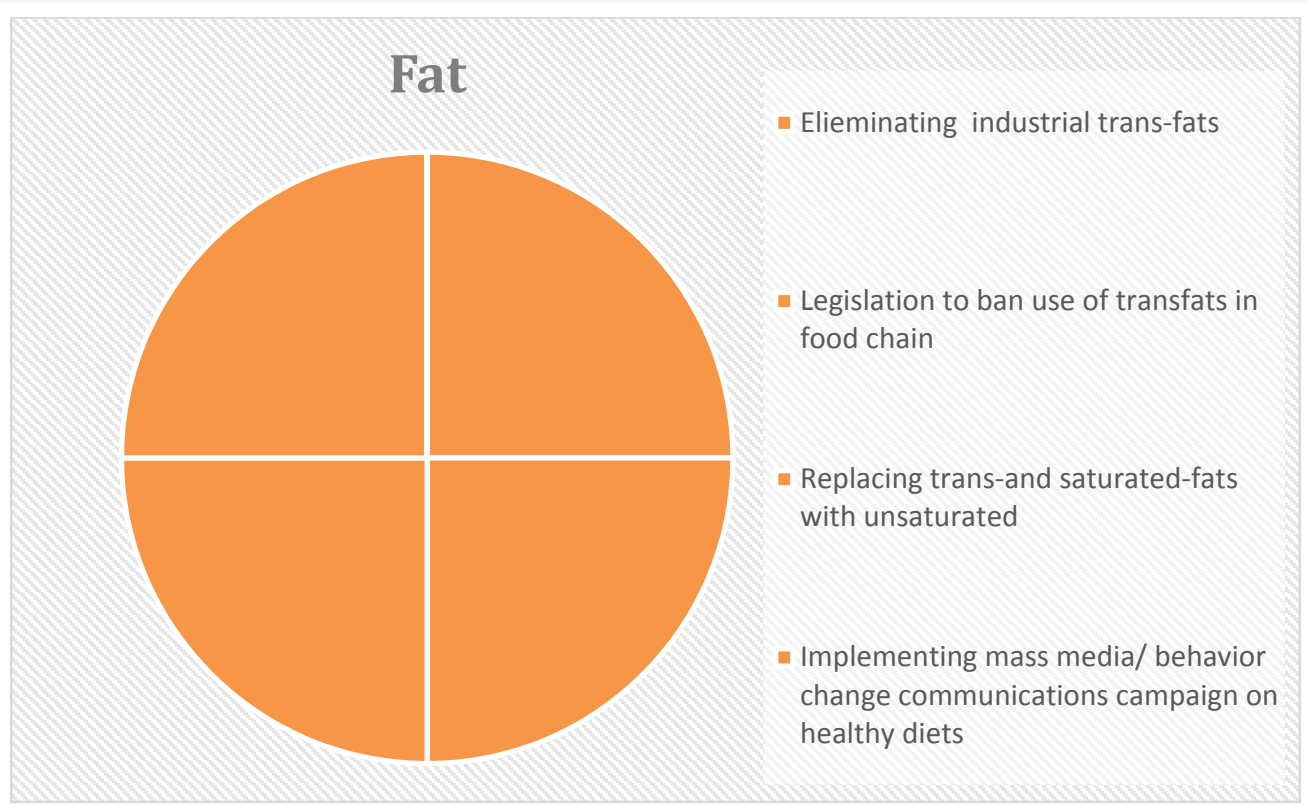

Fig. 3. The tran fat polices status in Iran based on best buys recommendations

green, only 1 is amber, and no policy is red. In 2016, the WHO officially selected Iran as a fast track country whose governance mechanism to combat NCDs was recognized along with few other countries to be premier and advanced at the global level (19) and the first in the Eastern Mediterranean region (20).

There are various reasons behind this progress. First, the highest level of political support led Iran to develop the National Action Plan for NCDs prevention and control in 2015 , aligned with WHO global targets as well as national priorities and evidence derived from national and subnational burden of diseases study (21). The plan was approved by the SCHFS, Iran's multisectoral mechanism, to ensure "health in all policies" approach, it and was announced by the President in February 2016. Consequently, the Ministry of Health and Medical Education (MOHME) established the Iranian noncommunicable diseases committee (INCDC), led by the Minister and membered by pioneer stakeholders, to make relevant policies, monitor the implementation, and scale up interventions to reduce premature death attributed to NCDs by $30 \%$ until 2030 . The INCDC has 9 subcommittees based on different aspects of prevention and control of NCDs, their risk factors, and national targets $(19,21)$.

Second, the INCDC advocated the dissemination of the national plan across the country through direct dialogue with the governors and related high officials across all 31 provinces in Iran. In addition, all medical universities were mandated to define their provincial action plan for prevention and control of NCDs, in line with the national plan and the global best practices. The subcommittee for monitoring within the INCDC was tasked to monitor the smooth implementation of the plans nationwide and provide food to improve their implementation.

Third, the INCDC approved a tailored WHO strategy for early screening of NCDs' risk factors and its low-cost treatment (PEN: Package of Essential Noncommunicable Diseases interventions), so-called IRaPEN. IRaPEN, included interventions to increase access to affordable medicines, guidance on practicing healthy habits, (eg, regular exercise and a healthy diet to control blood sugar), and active risk score assessment of cardiovascular diseases (19). The implementation of IraPEN began in 4 pilot cities and gradually expanded to the whole country. The ongoing health transformation plan (HTP) to reach universal health coverage (UHC) facilitated the implementation of the national action plan and enhanced political and public support to fulfill its goals in Iran. In particular, HTP led more than 95\% of citizens to enjoy basic health insurance, which increased the affordability of the needed services for NCDs.

Fourth, the MOHME has successfully managed to increase access to essential medicines for NCDs and distribute them through the public health and secondary care facilities across the country (19).

Fifth, in line with the Sixth National Development Plan in 2017, Iran's Minister of Health and Medical Education officially informed the WHO about Iran's commitment to allocate extra $€ 450$ million (US\$ 480 million) annual funds for prevention and control of NCDs during the next 5 years. Further, the Food and Drug Administration (FDA) affiliated with the MOHME, initiated a series of interventions to reduce the commercial risk factors of NCDs, ie, reformulating food products; traffic light labeling for sugar, salt and, fat on all shelves products; and restricting the import of palm oil or food products containing palm oil, all of which contributed to a health-enabling environment for making healthier foods more available (19).

Sixth, in 2016, the MOHME established the Deputy for Social Affairs, whose responsibility is ensuring community participation, increasing public awareness, and materializ- 
ing multisectoral collaboration for health. This newly-established governance mechanism has contributed to industrial interventions to reduce the burden of NCDs in Iran.

Per capita consumption of salt was 12 gram/day in Iran, 2 times more than the recommended global amount (Fig. 4) (22).

A recent 24-hour recall measure to estimate dietary intake showed that $53.6 \%$ of salt was used in a discretionary way at home, while bread was the biggest contributor to salt intake, providing $12 \%$ of the total intake. Cheese $(5.3 \%)$ and yoghurt drinks $(4.7 \%)$ were the next most important sources. There are 70000 bakeries in the country, present- ing a major challenge in ensuring that adequate health inspections of all bakeries are in place to verify salt reduction measures. The average consumption of bread is $320 \mathrm{~g} / \mathrm{day}$, but intake varies markedly between cities and rural areas; also, the salt content of bread varies markedly from $1.8 \%$ $2.3 \%$ in flour (22). Figure 5 shows daily salt intake from bread during 2014- 2018 in Iran.

Various regulatory measures were developed to reduce population salt intake by a revision of food standards and details, making Iran as the only country in the Eastern Mediterranean region of WHO implementing such regulatory measures (25). For instance, the national salt reduction plan has mandated the MOHME, in collaboration with other

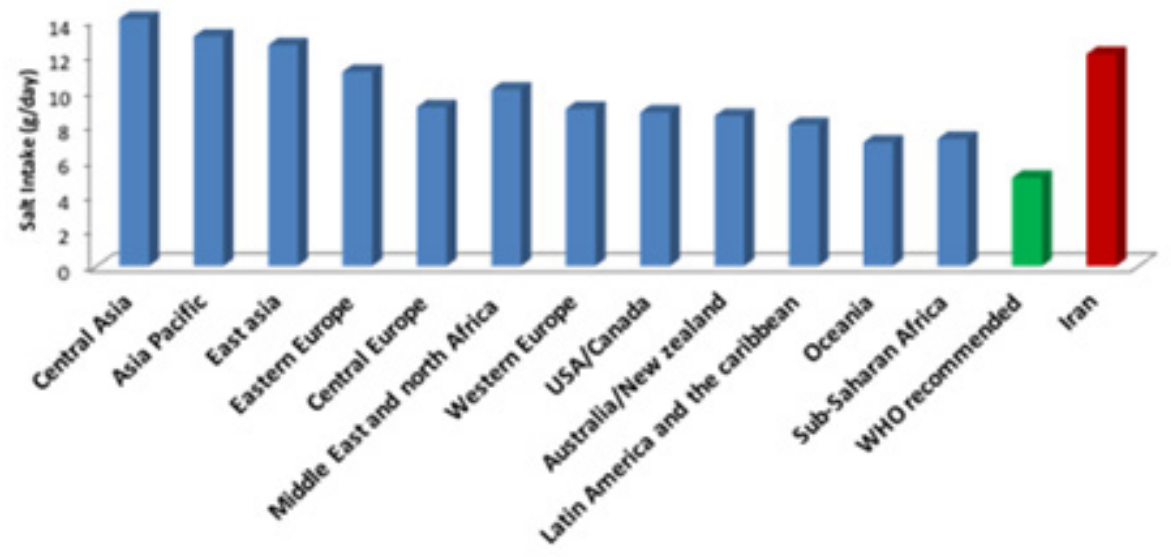

Source: J. Powles, S. Fahimi, R. Micha, S. Khatibzadeh, P. Shi, M. Ezzati, R.E. Engell, S.S. Lim, G. Danaei, D.

Mozaffarian, Global, regional and national sodium intakes in 1990 and 2010: a systematic analysis of $24 \mathrm{~h}$

uninary sodium excretion and dietary surveys worldwide, BMJ Open 3 (2013) 1-20.

Fig. 4. Global salt intakes before starting the plan (g/day). J. Powles,et al. 2013 (23).

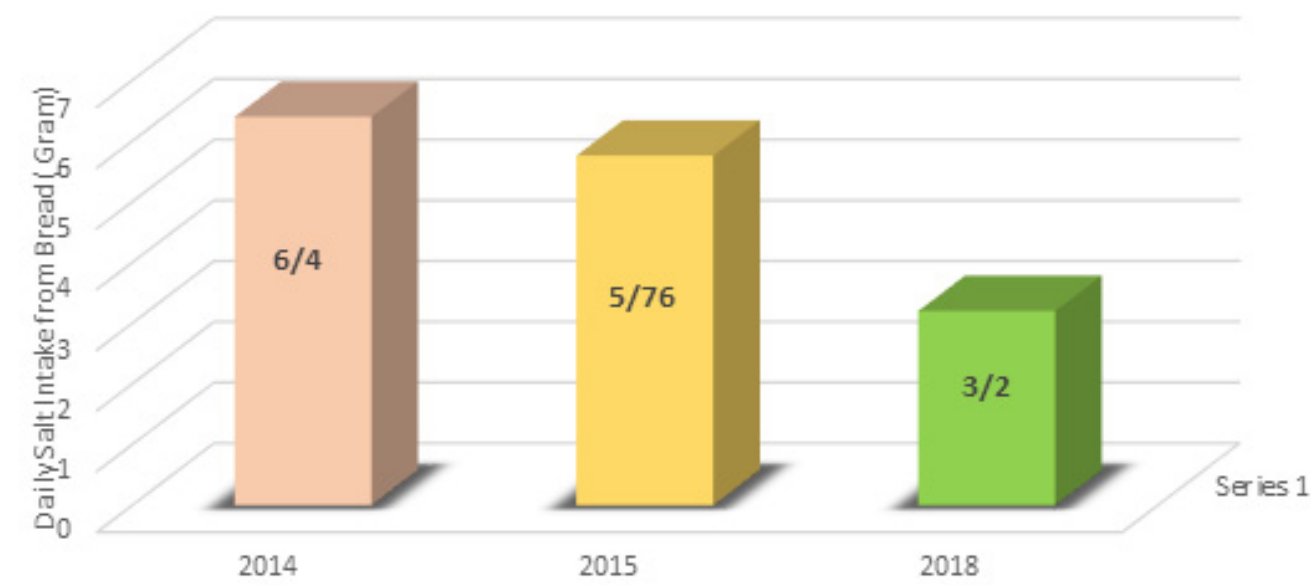

Source: Food and Drug Administration (FDA) of Iran, 2018. Available from :

http://fda.gov.ir/service

Fig. 5. Daily salt intake from bread during 2014-2018 in Iran. Food and Drug Administration (FDA) of Iran, 2018 (24). 
stakeholders, to conduct surveys to measure salt, sugar and oil consumption patterns of the population; to collaborate with the National Standards Organization in developing relevant food standards; to expand nutritional labelling by close cooperation with the food industry as a key partner; and to enhance the capacity of health workers and technical personnel across the 31 provinces of the country to materialize the aims of the plan (25), all of which has reduced salt consumption. A recent study showed that the mean of salt intake among Iranian population was $9.52 \mathrm{~g} /$ day, presenting almost $3 \mathrm{~g}$ /day reduction after implementing the plan (26). Figure 6 shows the salt content in different foods before and after plan in Iran.

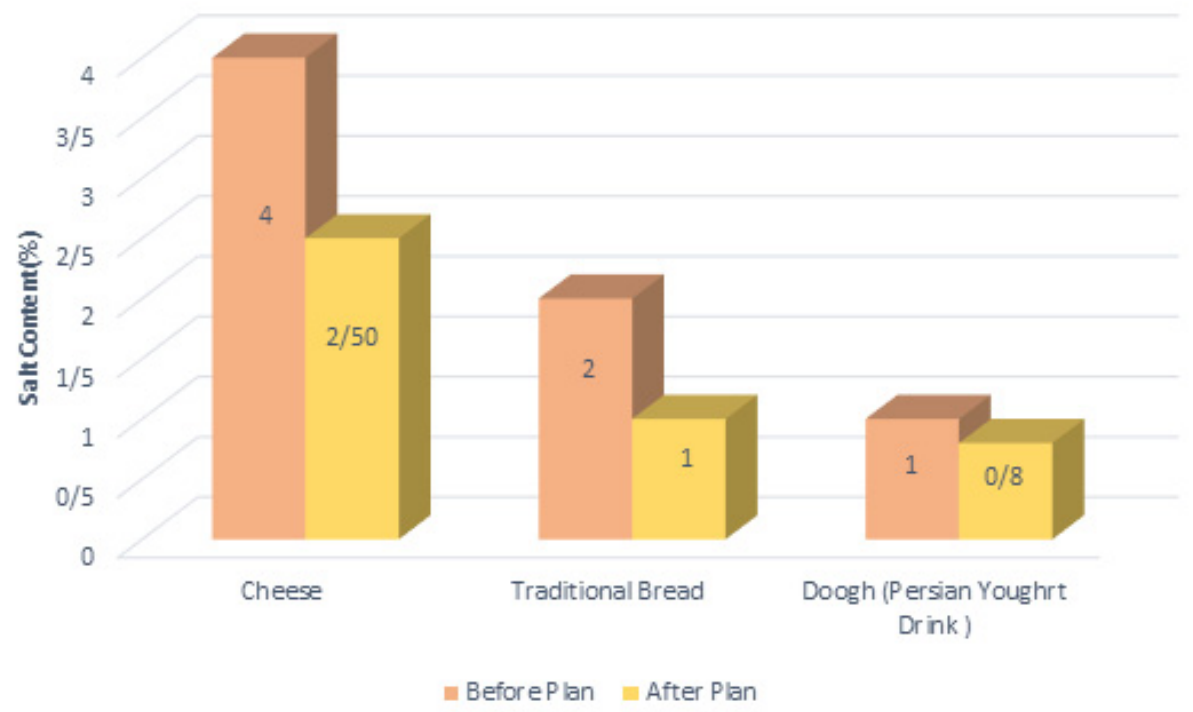

Source: Food and Drug Administration (FDA) of Iran, 2018. Available from : http://fda.gov.ir/service

Fig. 6. Food salt content changes in national regulation before and after the implementation of the plan in Iran. Food and Drug Administration (FDA) of Iran, 2018 (24).

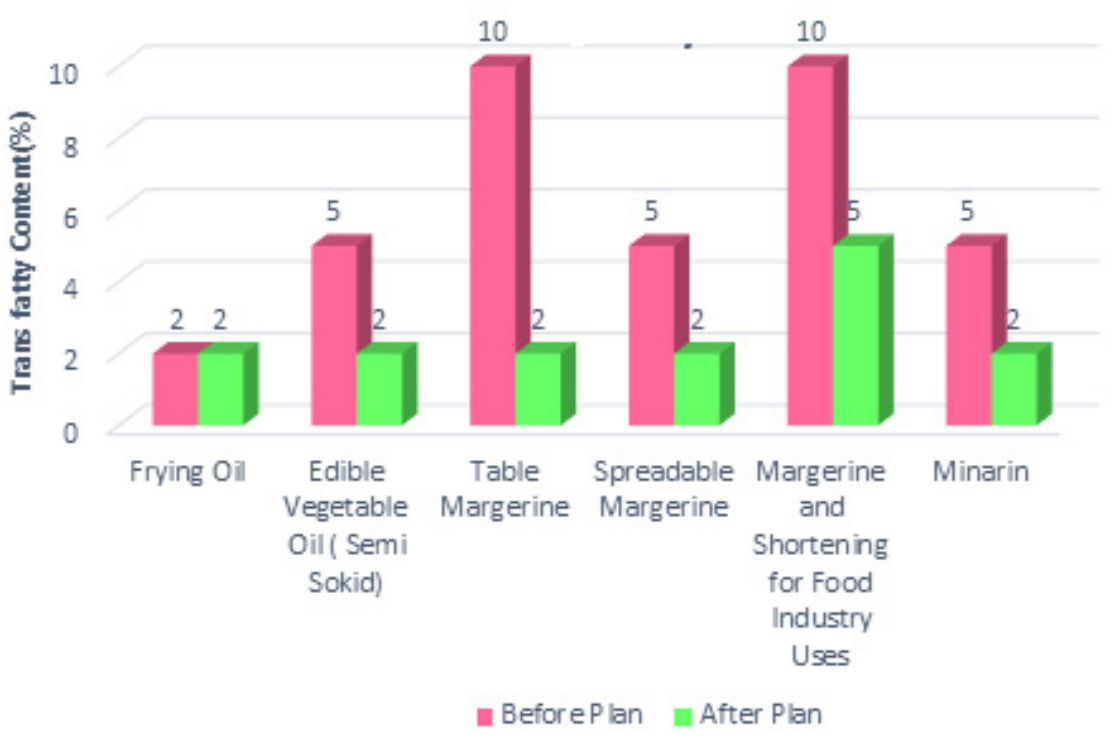

Source: Food and Drug Administration (FDA) of Iran, 2018. Available from : http://fda.gov.ir/service

Fig. 7. Trans fatty acids content before and after the implementation of the plan in Iran. Food and Drug Administration (FDA) of Iran, 2018 (24). 
Regarding trans-fat consumption, a national survey found that over $12 \%$ of calories consumed came from partially hydrogenated vegetable oils, the main source of trans fats in Iran. Trans fats contained more than a third of the fatty acids in those oils or almost $5 \%$ of daily calorie consumption, double the trans-fat intake in the United States of America in 2007 (25). To tackle the problem, in 2014, the SCHFS approved the standard revisions for trans fatty acids to reduce to less than $2 \%$ and saturated fatty acid to reduce to less than $25 \%$ in all fats and oils used in Iran. Further, Iran is the only country in the WHO Eastern Mediterranean region that has prepared regulatory measures through revision of food standards and specifications, aiming to reduce industrialized trans fatty acids in oil and margarine. To reduce saturated fatty acid intake, the Ministry of Trade was mandated to reduce the amount of imported palm oil, which reduced from $70 \%$ to $30 \%$ in 2014 (27).

FDA's recent data show that current trans-fat acid consumption is $1.5 \mathrm{~g} /$ day, equivalent to $0.7 \%$ of total daily energy, and saturated fatty acid consumption is $19 \mathrm{~g} /$ day, equivalent to $8.6 \%$ of total daily energy, indicating Iran has achieved its goals about trans-fat and saturated fat acid consumption (24). Figure 7 displays the trans fatty content in different foods before and after the implementation of the plan in Iran.

\section{Conclusion}

Policy-learning from national, regional, and global experiences is essential to manage the political economy of the main determinants of NCDs. In addition to technical solutions to combat NCDs, feasible and meaningful policy solutions, which are aligned with the political economy of each context, are crucial.

Our policy analysis indicates that Iran has formulated NCDs roadmap based on best buys recommendations, where required policies for reducing sugar, fat, and salt are in place (green). Nevertheless, some policies are more aspirational commitments than concrete measures, rendering the need for more actions, particularly structural interventions to address food reformulation, taxation, and marketing. NCDs are a complex and multidimensional phenomenon, whose tackling requires adoption of successful global experiences and tailoring best practices to be implemented at the local level.

\section{Acknowledgment}

The authors would like to thank the Iranian Food and Drug Administration (FDA) and the School of Public Health at Tehran University of Medical Sciences (TUMS) for general support and encouragement.

\section{Ethical considerations}

This study was approved by the ethical committee of Tehran University of Medical Sciences (TUMS) (approval number IR.TUMS.SPH.REC.1397.193). Both authors contributed equally to the manuscript and approved the final draft.
Conflict of Interests

The authors declare that they have no competing interests.

\section{References}

1 Bakhtiari A, Takian A. Majdzadeh R, Haghdoost Aa. Assessment and prioritization of the WHO "best buys" and other recommended interventions for the prevention and control of non-communicable diseases in Iran. BMC Public Health. 2020;20(1):1-6.

2. Noncommunicable diseases country profiles 2018. Geneva: World Health Organization; 2018. Licence: CC BY-NC-SA 3.0 IGO.

3. Mokdad AH, Forouzanfar MH, Daoud F, El Bcheraoui C, MoradiLakeh M, Khalil I, et al. Health in times of uncertainty in the eastern Mediterranean region, 1990-2013: a systematic analysis for the Global Burden of Disease Study 2013. Lancet Glob Health. 2016;4(10):e704e13.

4. Renshaw N, Dissard R, Beagley J. A breath of fresh air acting on the UN mandate to tackle air pollution. NCD Alliance. October 2018.

5. Lim SS, Vos T, Flaxman AD, Danaei G, Shibuya K, Adair-Rohani H, et al. A comparative risk assessment of burden of disease and injury attributable to 67 risk factors and riskfactor clusters in 21 regions, 1990e2010: a systematic analysis for the Global Burden of Disease Study 2010. Lancet. 2013;380(9859):2224e60.

6. 2013-2020 Action Plan for the Global Strategy for the Prevention and Control of Noncommunicable Diseases. Geneva, Switzerland: World Health Organization; 2013.

7. Roberts NL, Mountjoy-Venning WC, Anjomshoa M, Banoub JAM, Yasin YJ. GBD 2017 Disease and Injury Incidence and Prevalence Collaborators. Global, regional, and national incidence, prevalence, and years lived with disability for 354 diseases and injuries for 195 countries and territories, 1990-2017: a systematic analysis for the Global Burden of Disease Study (vol 392, pg 1789, 2018). Lancet. 2019;393(10190):E44-E.

8. Naghavi M, Abajobir AA, Abbafati C, Abbas KM, Abd-Allah F, Abera $\mathrm{SF}$, et al. Global, regional, and national age-sex specific mortality for 264 causes of death, 1980-2016: a systematic analysis for the Global Burden of Disease Study 2016. Lancet. 2017;390(10100):1151-210.

9. Institute for Health Metrics and Evaluation, University of Washington (2018), Global burden of diseases 2016. https://vizhub.healthdata. org/gbd-compare/

10. Global burden of Diseases. Washington, Institute of Health Metric and Evaluation; 2014, Available from: http://vizhub.healthdata.org/ gbd-compare/.[Cited 2016 Sep 3].

11. Institute for Health Metrics and Evaluation. University of Washington Center for Health Trends and Forecasts. 2018. http://www. healthdata.org/iran

12. David J, Hunter KSR. Noncommunicable diseases. N Engl J Med. 2013;

369:1336-43

13. Peykari N, Djalalinia S, Qorbani M, Sobhani S, Farzadfar F, Larijani B. Socioeconomic inequalities and diabetes: a systematic review from Iran. J Diabetes Metab Disord. 2015;14:8.

14. Report on the Consultation on developing strategic directions for salt and fat reduction in the Eastern Mediterranean Region. WHOEM/NUT/260/E.

15. Swinburn B, Sacks G, Vandevijvere S, Kumanyika S, Lobstein T, Neal B, et al. INFORMAS (I nternational $\mathrm{N}$ etwork for $\mathrm{F}$ ood and $\mathrm{O}$ besity/non-communicable diseases $\mathrm{R}$ esearch, $\mathrm{M}$ onitoring and $\mathrm{A}$ ction S upport): overview and key principles. Obes rev. 2013;14:1-12.

16. Hawkes C. Food policies for healthy populations and healthy economies. BMJ. 2012;344:e2801.

17. Gilson L, Raphaely N. The terrain of health policy analysis in low and middle income countries: a review of the literature 1994-2005. Paper presented to a Workshop on Health Policy Analysis, London, 21-22 May 2007.

18. Tashakkori A, Teddlie C. Handbook of mixed methods in Social \& Behavioral Research. SAGE Ltd. 2013:297-320.

19. Mogalakwe M. The use of documentary research methods in social research. Afr Soc Rev. 2016;10(1):221-230.

20. World Health Organization. Islamic Republic of Iran on a Fast-Track to Beating Noncommunicable Diseases; 2017. Available from: http:// www.who.int/features/2017/iran-noncommunicable-diseases/en/.

21. Noncommunicable Diseases Progress Monitor 2015. Geneva: World 
Policy analysis against NCDs in Iran

Health Organization; 2015. Available from: http://www.who.int/nmh/ media/ncdprogress-monitor/en/.

22. Peykari N, Hashemi H, Dinarvand R, Haji-Aghajani M, Malekzadeh R, Sadrolsadat A, et al. National action plan for non-communicable diseases prevention and control in Iran; a response to emerging epidemic. J Diabetes Metab Disord. 2017;16(1):3.

23. Report on the Technical consultation on salt and fat reduction strategies in the Eastern Mediterranean Region. Tunis, Tunisia. 30-31 March 2015

24. Powles J, Fahimi S, Micha R, Khatibzadeh S, Shi P, Ezzati M, et al. Global, regional and national sodium intakes in 1990 and 2010: a systematic analysis of $24 \mathrm{~h}$ urinary sodium excretion and dietary surveys worldwide. BMJ Open. 2013;3(12).

25. Food and Drug Administration (FDA) of Iran, 2018. Available from: http://fda.gov.ir/service

26. Rezaeia Sh, Mahmoudia Z, Sheidaeia A, Aryana Z, Mahmoudia N, Gohari K. et al. Salt intake among Iranian population: the first national report on salt intake in Iran. J Hypertens. 2018;36.

27. Peymani P, Joulaie H, Zamiri N, Ahmadi SM, Dinarvand R, Hosseini $\mathrm{H}$, et al. Iran's experience on reduction of trans-fatty acid content in edible oils. Middle-East J Sci Re. 2012;11(9):1207-11. 